\title{
Automated manufacturing of large, three-dimensional CFRP parts from dry textiles
}

\author{
Authors: \\ TOBIAS GERNGROSS, tobias.gerngross@dlr.de, +49 821-319874-1040 \\ DOROTHEA NIEBERL, dorothea.nieber|@dlr.de, +49 821-319874-1056 \\ German Aerospace Center \\ Institute of Structures and Design \\ Center for Lightweight Production Technology (ZLP) \\ Am Technologiezentrum 4 \\ 86159 Augsburg, Germany
}

\section{Acknowledgements}

We would like to thank our colleagues at the Center for Lightweight Production Technologies for their excellent work and endurance. In particular we'd like to name S. Dutta, J. Faber, P. Kaufmann, M. Kiessig, M. Körber, F. Krebs, L. Larsen, S. Nuschele, T. Schmidt, C. Schmidt-Eisenlohr, M. Schönheits.

Work on this automation approach is currently done by a fairly large number of people and we enjoyed being part of this group. Our gratitude goes to our project partners and sub-contractors at Premium Aerotec GmbH, Fraunhofer IWU-RMV, J. Schmalz GmbH, University of Augsburg, Kisters AG.

We're grateful for the financial support provided by the Federal Ministry for Economic Affairs and Energy (BMWi), the Federal State of Bavaria, and the City of Augsburg. 


\section{Summary}

High-performance carbon fiber reinforced plastics (CFRP) see a continuous intersectoral growth of their share in structural weight. However, the key issue of significant high costs remains persistent. The Center for Lightweight Production Technologies addresses this problem with solutions for process automation. This paper presents several automation approaches along the process chain for the manufacturing of large CFRP parts. This includes three devices for a robust preforming process, an offline programming environment and a mechanized lay-up system for vacuum bagging. For production-integrated quality assurance two measurement devices and a powerful data management system is presented. The final validation phase finishes with a cured full-scale part.

\section{Introduction}

The manufacturing of large CFRP parts in aerospace still involves many manual process steps, leading to reduced reproducibility and the necessity of rework. In addition a quality inspection in hindsight does not allow for any adjustments during the production process. Apart from high material costs these are the most significant cost drivers for aerospace CFRP parts (ref. [1]). Process steps that are particularly time and cost intensive include the lay-up of preform and stiffeners, the lay-up of auxiliary materials for resin infusion and the assessment of measurement results from quality assurance. This paper addresses the key cost drivers by presenting the results from the development process in the project AZIMUT.

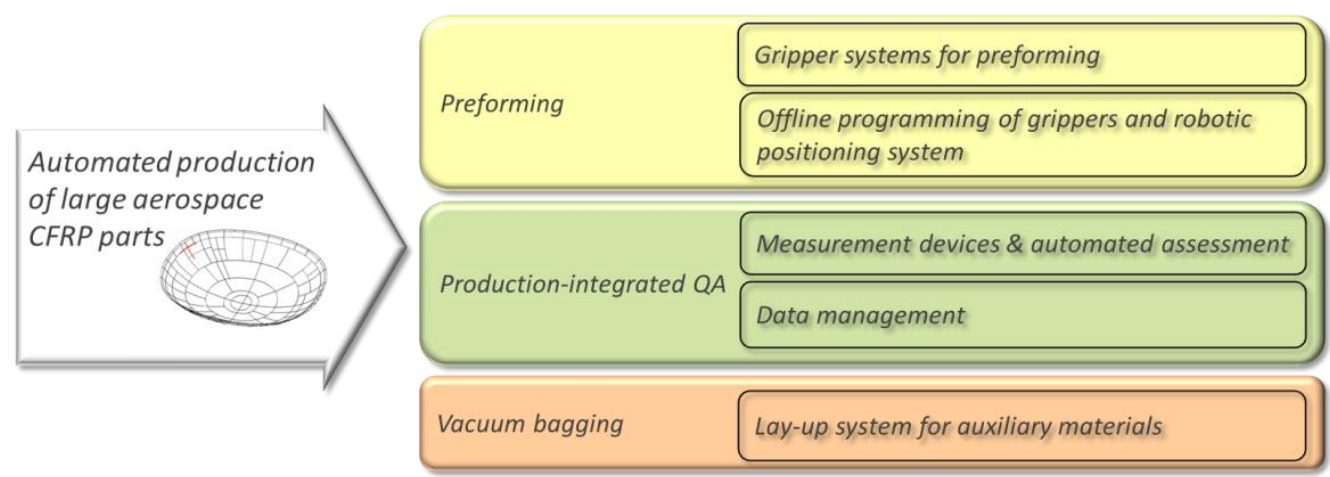

Figure 1: Key contributions to an automated production of large CFRP parts

The presented automation approach combines three major disciplines; preforming, quality assurance and vacuum lay-up, see Figure 1. Firstly, the preforming process requires the development of suitable gripper systems for pick-and-place of textile cut-pieces to build a dry, 3D preform. Three different gripper approaches have been followed to assess their underlying pick-and-drape principles. Secondly, production integrated quality assurance during preforming is essential for verification of preforming tolerances. An automated inline measurement evaluation allows for corrective actions in case of detected errors in fiber angle or cut-piece position. Thirdly, the textile preform requires vacuum bagging for resin infusion, where the lay-up consists of cut-pieces from a variety of auxiliary materials. Process optimization involved the development of a positioning device for a pre-tailored infusion membrane. Finally, the manufacturing of a full-scale demonstrator of a large, doubly curved aerospace component serves as validation case, see Figure 2.

\section{Grippers and Quality Assurance for Process Automation}

\section{Production Process for a large, representative CFRP Part}

The development of automation approaches in this work has been tailored to a large bulkhead geometry with about $4 \mathrm{~m}$ diameter. This pressure bulkhead has been chosen as representative demonstrator since dimensions and curvatures define the complexity and the challenge for the development of automation solutions. The doubly curved body shows a continuous variation of radii 
of curvature between 1.3 and $3.3 \mathrm{~m}$, see Figure 2, left. The preforming is conducted on a female tooling, where dry textile weave or non-crimp fabric is to be draped. The ply book provides good diversity in 25 cut-pieces that vary in size and shape. A selection of sample contours has been illustrated on the tooling surface in Figure 2 . In addition the part includes 8 individual stiffeners with local thickness increase and tight, local radii along their boundaries. For all these features the challenges due to tolerances and handling requirements are based on existing industrial manufacturing processes.

Due to dimension, curvatures, ply book, stiffeners and requirements, the complexity and challenges in this demonstrator were deemed to be representative for large aerospace structures. This will ease the transfer of capabilities and experiences to other composite parts that might be made of dry textiles. In Aerospace this may include geometries of fuselages, wings, tailplanes, nacelles, or cargo doors. Potential applications in other composite industries with large doubly curved structures may be found in automotive with roofs or bonnets, or in wind energy with blade roots, shells or spars.

The assigned manufacturing process for thermosets uses dry textile preforms and VAP resin infusion. Figure 3 gives an overview of the process, where the two process steps "preforming" and "vacuum bagging" are further divided in subsequent tasks. The process step "preforming" is being repeated for each cut-piece in a ply book. Subsequent production integrated QA allows assessment and documentation of fiber angles and cut-piece boundary positions for each preform layer.

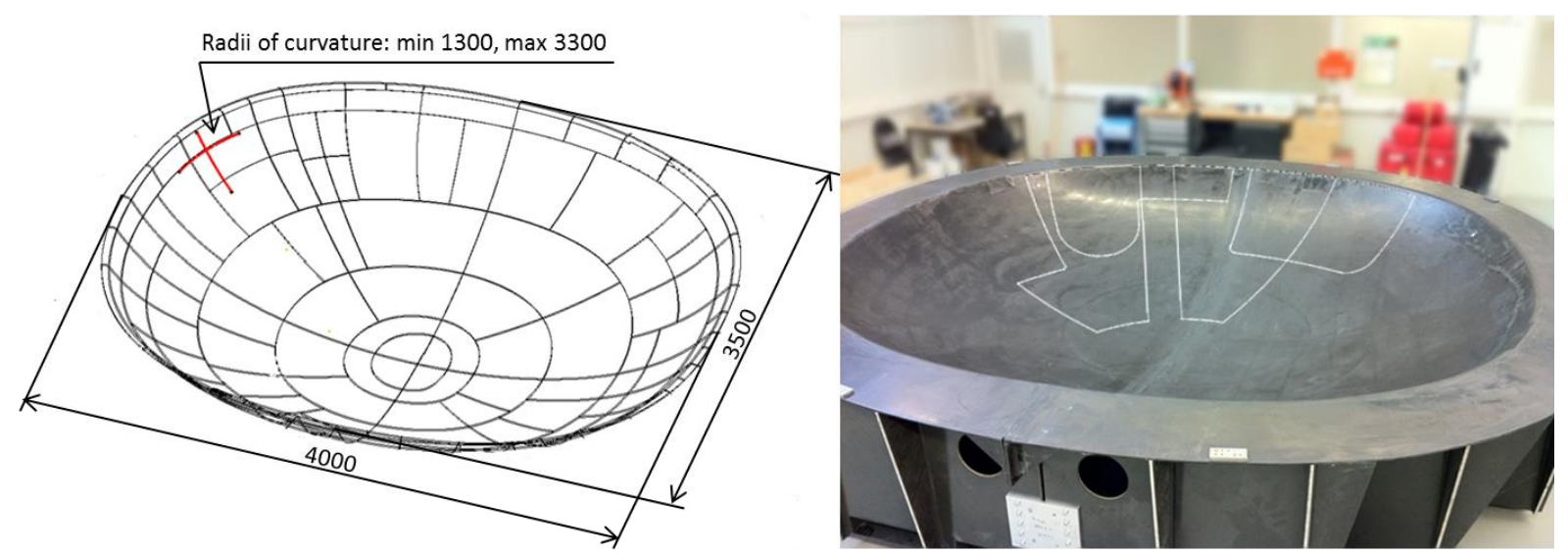

Figure 2: Demonstrator geometry with double curvature (I), Tooling with contours of sample cutpieces ( $r$ )

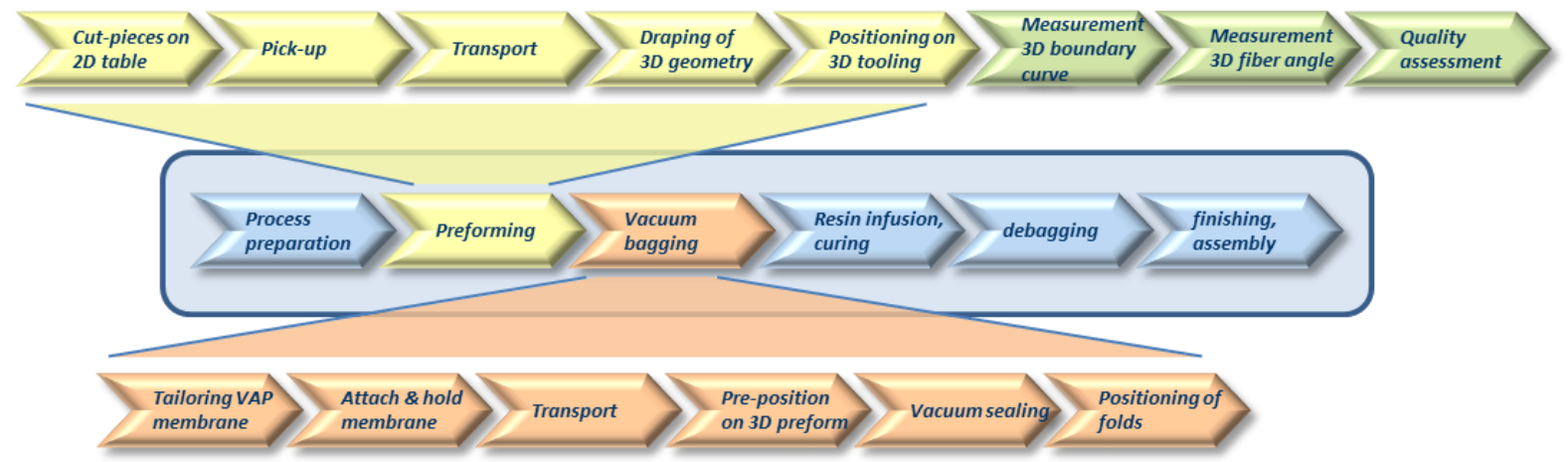

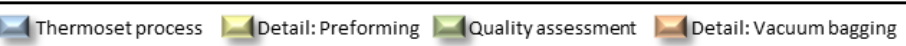

Figure 3: Production process for fiber composite components with resin infusion 


\section{Development of Gripper Systems for preforming}

The lay-up and cut-piece geometries are defined in a ply book. Process preparation provides these cut-pieces from dry textile weave or non-crimp fabric on a 2D table in known position and orientation. A gripper system then has to perform four process steps; pick-up, transport, draping and final positioning on the 3D tooling. A particular challenge is the draping of the flat 2D textile to $3 \mathrm{D}$ double curvature whilst meeting the requirements for boundary curve positions and local fiber angles.

In the recent past a variety of approaches for handling of non-rigid, textile cut-pieces has been developed. Examples for automation systems for flexible preforming of single-layer cut-pieces (see Figure 4, ref. [2]) are two robot-based end-effectors for handling and draping of textiles (see Figure 5, ref. [3]), both developed by Fraunhofer IWB, or a gripper system for the assembly of large CFRP parts for aircraft fuselages demonstrated by Premium Aerotec (ref. [4]). As none of the aforementioned solutions is suitable for draping and lay-up of cut-pieces into a doubly curved tooling with radii up to $1.3 \mathrm{~m}$ the development of a new gripper system was deemed to be necessary.

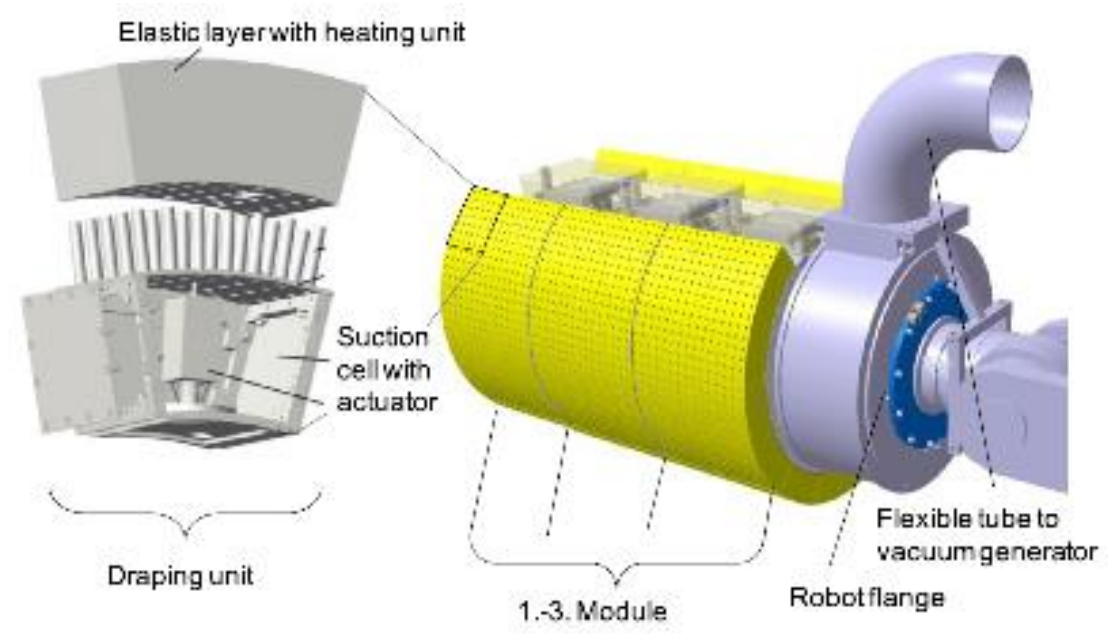

Figure 4: Automation system for flexible preforming of single layer cut-pieces, Fraunhofer IWB, ref. [2]

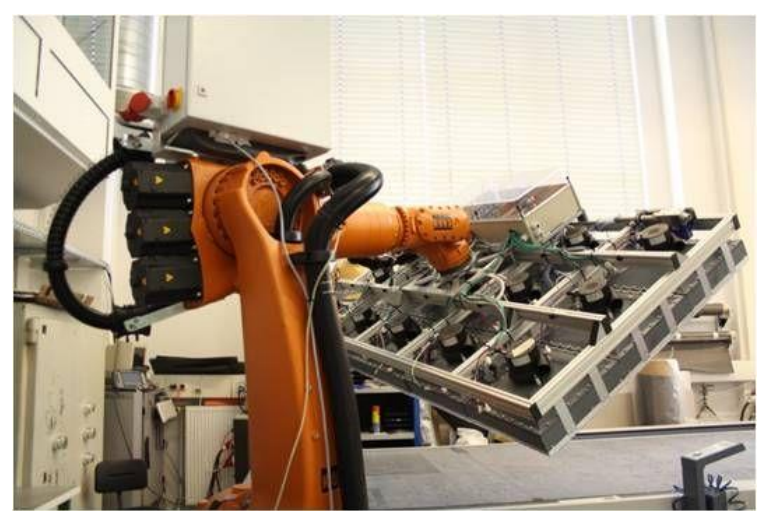

Figure 5: Flexible robot-based end-effector for handling and draping of textile cut-pieces, Fraunhofer IWB, ref. [3]

Three different principles have been chosen for further investigation. Table 1 highlights the key features regarding their gripping and draping functions and their structural setup. Each concept has its pronounced advantages, but also challenges that were to be solved during development, see Table 1.

In addition to the overall kinematics of a gripper system the actual gripping function can be realized by various active principles. Suitable gripper technology can be acquired from commercial suppliers, 
e.g. Schmalz $\mathrm{GmbH}$. The choice of the particular gripper technology is based on the advantages and disadvantages of mechanical, adhesive or pneumatic grippers (see student research project, ref. [5] and conference lecture, ref. [6]). Optimal gripper solutions consider material properties, geometrical and physical conditions imposed by the chosen principle. Furthermore, requirements given by aerospace industry had to be taken into consideration, like contortion free contact with the surface of the textiles.

\begin{tabular}{|c|c|c|c|}
\hline & Grid Gripper & Foam Gripper & Modular Surface \\
\hline $\begin{array}{l}\text { Draping } \\
\text { principle }\end{array}$ & $\begin{array}{l}\text { Gripper structure shows } \\
\text { shear behavior similar to } \\
0^{\circ} / 90^{\circ} \text { textile }\end{array}$ & $\begin{array}{|lr|}\text { Flexible foam } & \text { interface } \\
\text { allows final } & \text { draping by } \\
\text { applying } & \text { surface } \\
\text { pressure } & \end{array}$ & $\begin{array}{l}\text { Large number of gripper } \\
\text { modules can adjust to } \\
\text { 3D tooling surface }\end{array}$ \\
\hline $\begin{array}{l}\text { Structural } \\
\text { main } \\
\text { components }\end{array}$ & $\begin{array}{l}\text { Flexible beams in } 0 \% 90^{\circ} \\
\text { orientation, hinges as } \\
\text { beam connectors }\end{array}$ & $\begin{array}{l}\text { Rigid structure with } 2 \\
\text { tiltable corners for pre- } \\
\text { adjustment, thick flexible } \\
\text { foam padding }\end{array}$ & $\begin{array}{l}1 \mathrm{x} \text { backbone carrying } \\
15 x \text { ribs, each rib carries } \\
\text { self-contained gripper } \\
\text { modules }\end{array}$ \\
\hline $\begin{array}{l}\text { Gripper } \\
\text { technology }\end{array}$ & $\begin{array}{lr}32 x & \text { off-the-shelf } \\
\text { pneumatic } & \text { Coanda } \\
\text { grippers } & \\
\end{array}$ & $\begin{array}{l}7 x \text { electric radial fans } \\
\text { combined with open-cell } \\
\text { foam }\end{array}$ & $\begin{array}{l}127 x \text { electric Coanda } \\
\text { grippers }\end{array}$ \\
\hline $\begin{array}{l}\text { Expected } \\
\text { advantages }\end{array}$ & $\begin{array}{l}\text { lightweight system, } \\
\text { setup from off-the-shelf } \\
\text { components only }\end{array}$ & $\begin{array}{lrr}\text { gripper } & \text { system } & \text { requires } \\
\text { only } & \text { rough } & \text { pre- } \\
\text { adjustment, } & \text { passive } \\
\text { draping by flexible foam } \\
\text { padding }\end{array}$ & $\begin{array}{lr}\text { precise } & \text { adjustment of } \\
\text { gripper } & \text { surface, } \\
\text { individual gripper forces } \\
\text { allow local hold/slide- } \\
\text { settings }\end{array}$ \\
\hline $\begin{array}{l}\text { Key } \\
\text { challenges }\end{array}$ & $\begin{array}{l}\text { gripper positions along } \\
\text { the grid for optimum } \\
\text { draping results }\end{array}$ & $\begin{array}{l}\text { weight \& } \quad \text { power } \\
\text { intensive, draping result } \\
\text { visible only after } \\
\text { removipper } \\
\end{array}$ & $\begin{array}{l}\text { weight \& power } \\
\text { intensive, high effort for } \\
\text { adjustment of gripper } \\
\text { force at each module }\end{array}$ \\
\hline
\end{tabular}

Table 1: Three gripper approaches for preforming

The sketches in Figure 6 illustrate the three draping concepts. The Grid Gripper's key structural component is a grid of 4 by 4 flexible beams in $0 \% 90^{\circ}$ orientation with hinges at their crossing points (ref. [7]). Anywhere along these beams a number of gripper modules can be attached. Reshaping this 2D grid to a doubly curved 3D geometry requires an out-of-plane deformation, which is achieved by holding the four outer corners and applying a force at the center of the grid. Out-of-plane deformation causes minor changes in shear angles at the beam crossing points. These shear angles correspond exactly to the shearing in a $0 \% 90^{\circ}$ weave or non-crimp fabric during draping. This approach provides a gentle draping method.

The Foam Gripper features a rigid main structure with a pre-set single curvature plus two tiltable corners for coarse adjustment of the draping surface. The final draping is done by applying pressure onto the gripper surface that is made of thick, flexible foam padding (ref. [8]). The compression of the foam compensates any remaining gaps between gripper and tooling surface. The gripping function comes from radial fans that generate suction through the open-cell foam. This passive draping method guarantees distributed surface pressure and complete surface contact between gripper and tooling.

The closest representation of the tooling surface can be achieved by the third concept, the Modular Surface Gripper. Its main structure consists of an adjustable backbone that supports 15 adjustable ribs on either side. Each rib carries a number of self-contained gripper modules. This leaves a total of 127 gripper modules that correlate to form the 3D preform geometry. A key feature is the 
individual adjustment of each module's gripping force such that the textile cut-piece is either being locally held in place or allowed to slide for the 3D draping.
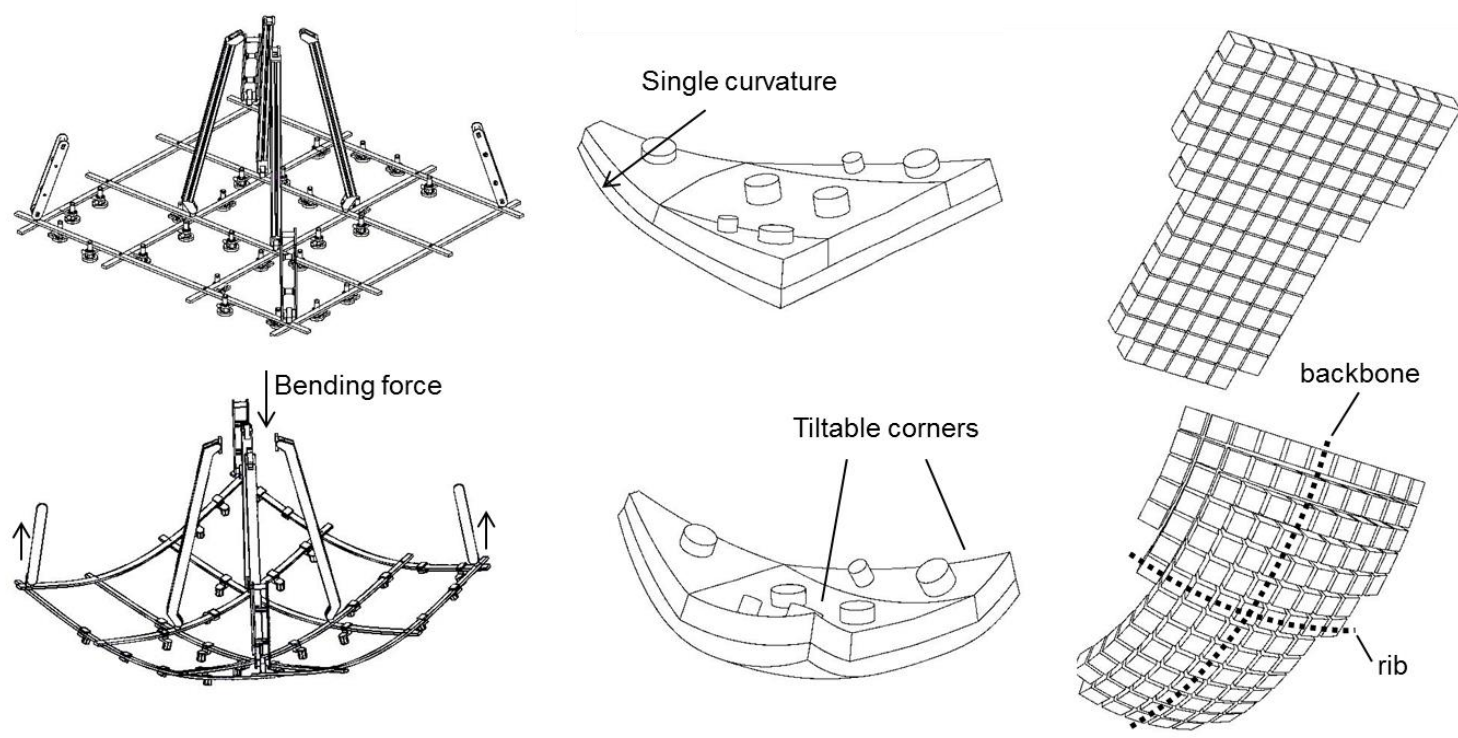

Figure 6: Three draping concepts in 2D and 3D configuration (from left: Grid Gripper, Foam Gripper, Modular Surface)

\begin{tabular}{|c|c|c|c|}
\hline & Grid Gripper & Foam Gripper & Modular Surface \\
\hline Dimension & $1.45 \times 1.45 \mathrm{~m}$ & $1.90 \times 1.60 \mathrm{~m}$ & $1.78 \times 1.35 \mathrm{~m}$ \\
\hline Weight & $112 \mathrm{~kg}$ & $150 \mathrm{~kg}$ & $200 \mathrm{~kg}$ \\
\hline $\begin{array}{l}\text { Energy } \\
\text { supply }\end{array}$ & $\begin{array}{ll}5 \mathrm{~V}, \quad 200 \mathrm{~mA} & \text { for } \\
\text { controls, } & \\
\text { Compressed } & \text { air } \\
5000 \mathrm{~L} \text { min, } 6 \text { bar } & \\
\text { EtherNet (EtherCat) } & \end{array}$ & \begin{tabular}{|lrr}
$48 \mathrm{~V}$, & 32.5 & $\mathrm{~A}$, \\
$230 \mathrm{~V}$, & & $22.5 \mathrm{~A}$ \\
$24 \mathrm{~V}$, & & $89 \mathrm{~A}$, \\
EtherNet & (ProfiNet)
\end{tabular} & $\begin{array}{l}2 \times 24 \mathrm{~V}, 100 \mathrm{~A} \\
1 \times 24 \mathrm{~V}, 40 \mathrm{~A} \\
1 \times 48 \mathrm{~V}, 21 \mathrm{~A} \\
\text { EtherNet (EtherCat) }\end{array}$ \\
\hline Actuators & $\begin{array}{l}1 \text { linear actuator, } \\
32 \text { Coanda modules }\end{array}$ & $\begin{array}{l}7 \text { electrical fans, } 4 \\
\text { linear actors }\end{array}$ & $\begin{array}{l}3 \text { servos for backbone, } \\
12 \text { servos for ribs, } \\
127 \text { electrical Coanda } \\
\text { modules }\end{array}$ \\
\hline Controls & $\begin{array}{l}\text { directly controlled by } \\
\text { robot (no additional } \\
\text { logic on gripper) }\end{array}$ & $\begin{array}{|ll|}\text { decentralized } & \\
\text { programmable } & \text { logic } \\
\text { controller } & \text { (PLC) } \\
\text { (Siemens S7) } & \\
\end{array}$ & $\begin{array}{l}\text { decentralized PLC (Beckhoff } \\
\text { TwinCat), } \\
127 \text { Coanda modules via } 4 x \\
\text { sub-controllers }\end{array}$ \\
\hline
\end{tabular}

Table 2: Key figures of gripper systems

The three approaches have been further developed towards a successful hardware validation together with Fraunhofer IWU-RMV and J. Schmalz GmbH. The resulting hardware in Figure 7 shows the grippers in a 3D configuration during operation in our robotic test bed. Table 2 summarizes the key figures of the three systems. 

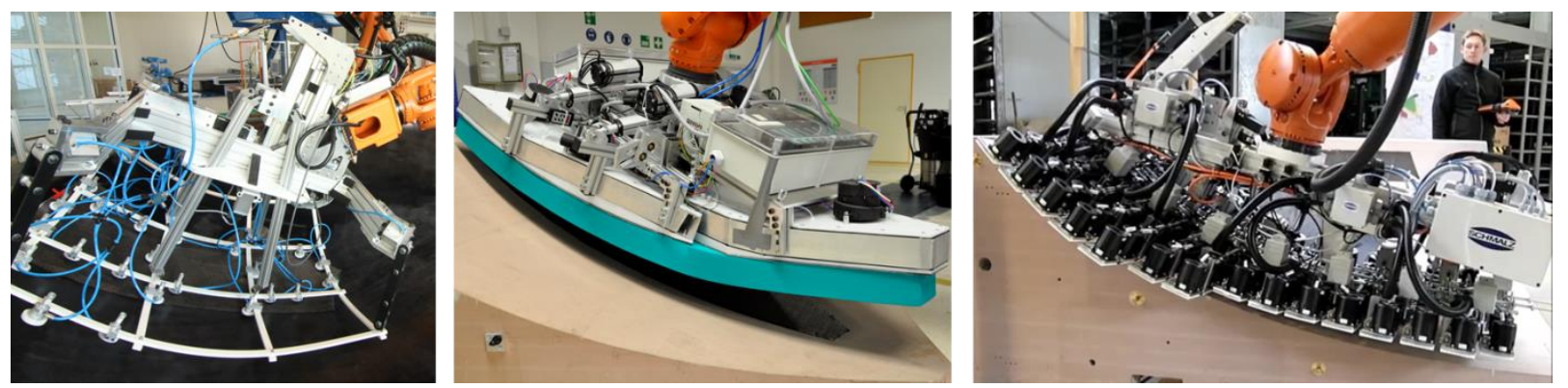

Figure 7: Hardware demonstrators of three preforming grippers (from left: Grid Gripper, Foam Gripper, and Modular Surface Gripper)

With the gripper hardware ready for operation the set of cut-pieces need to be draped on the 3D tooling surface. The draping results strongly depend on the optimum draping strategy for each gripper system. The key performance indicators were the accuracy of 3D boundary curve positions and local fiber angles. Table 3 summarizes the different strategies for pick-up and draping.

\begin{tabular}{|c|c|c|c|}
\hline & Grid Gripper & Foam Gripper & Modular Surface \\
\hline \multirow{4}{*}{ 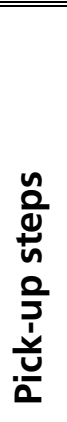 } & $\begin{array}{lll}\begin{array}{l}\text { Gripper in } \\
\text { configuration }\end{array} & \text { 2D start } \\
\end{array}$ & $\begin{array}{l}\text { Gripper starts with single } \\
\text { curvature }\end{array}$ & $\begin{array}{l}\begin{array}{l}\text { Gripper in } \\
\text { configuration }\end{array} \\
\end{array}$ \\
\hline & Pick-up position on table & $\begin{array}{l}\text { Gripper in start position on } \\
\text { table }\end{array}$ & Pick-up position on table \\
\hline & $\begin{array}{l}\text { Activate all gripper modules } \\
\text { at once }\end{array}$ & Pick-up by rolling motion & $\begin{array}{l}\text { Activate all gripper modules } \\
\text { at once }\end{array}$ \\
\hline & & $\begin{array}{l}\text { Sequentially activate radial } \\
\text { blowers during rolling } \\
\text { motion }\end{array}$ & \\
\hline \multirow{4}{*}{$\begin{array}{l}\frac{n}{0} \\
\frac{a}{n} \\
0 \\
\frac{c}{0} \\
\frac{0}{0} \\
\frac{0}{0}\end{array}$} & $\begin{array}{l}1 \text { linear actuator deforms } \\
\text { grid out-of-plane }\end{array}$ & $\begin{array}{l}4 \text { linear actors tilt } 2 \text { corners } \\
\text { of gripper structure }\end{array}$ & $\begin{array}{ll}\text { Each gripper module with } \\
\text { individual force for } \\
\text { hold/slide function }\end{array}$ \\
\hline & $\begin{array}{l}\text { textile cut-piece shears and } \\
\text { drapes according to grid- } \\
\text { structure }\end{array}$ & $\begin{array}{l}\text { textile cut-piece slides and } \\
\text { shears on corner surfaces }\end{array}$ & $\begin{array}{l}132 \quad \text { gripper modules } \\
\text { simultaneously adjust to 3D } \\
\text { geometry }\end{array}$ \\
\hline & $\begin{array}{l}\text { Gripper in 3D configuration } \\
\text { positions fully draped cut- } \\
\text { piece on tooling surface }\end{array}$ & $\begin{array}{l}\text { Gripper in 3D config. } \\
\text { applies pressure force on } \\
\text { tooling surface; foam } \\
\text { compensates gaps and } \\
\text { molds cut-piece }\end{array}$ & $\begin{array}{l}\text { Cut-piece drapes with } \\
\text { morphing gripper surface, } \\
\text { cut-piece held in position by } \\
\text { selected gripper modules }\end{array}$ \\
\hline & & & $\begin{array}{l}\text { Gripper in 3D configuration } \\
\text { positions fully draped cut- } \\
\text { piece on tooling surface }\end{array}$ \\
\hline
\end{tabular}

Table 3: Sequential steps for pick-up and draping

\section{Offline Programming of Grippers and Robotic Systems}

The pick-up and draping strategies in Table 3 define the gripper movements to be executed by, generally speaking, a positioning system. Typically a robotic system will be used to control gripper poses (pose $=$ position and orientation) and any actuators. Here, for test series and final validation at the DLR two robotic cells were utilized, a 2-robot-system on a floor-mounted linear axis and a larger multi-robot-system with robots headfirst for improved accessibility (ref. [9]).

For each individual cut-piece (and each gripper) the robotic trajectories and gripper settings may be determined either by manual teaching or alternatively in an offline programming environment. However, due to the number of different cut-pieces, gripper adjustments and gripper movements a 
suitable offline programming solution means significant time-savings. Together with the ISSE at the University of Augsburg a software solution has been developed for the three gripper systems.

Premise to an accurate process simulation is a realistic representation of the robotic cell, the gripper system (Figure 8), the 2D and 3D tooling, and their coordinate systems. Starting with this real world representation the only remaining input is a ply book that contains 2D and 3D representations of the cut-pieces.

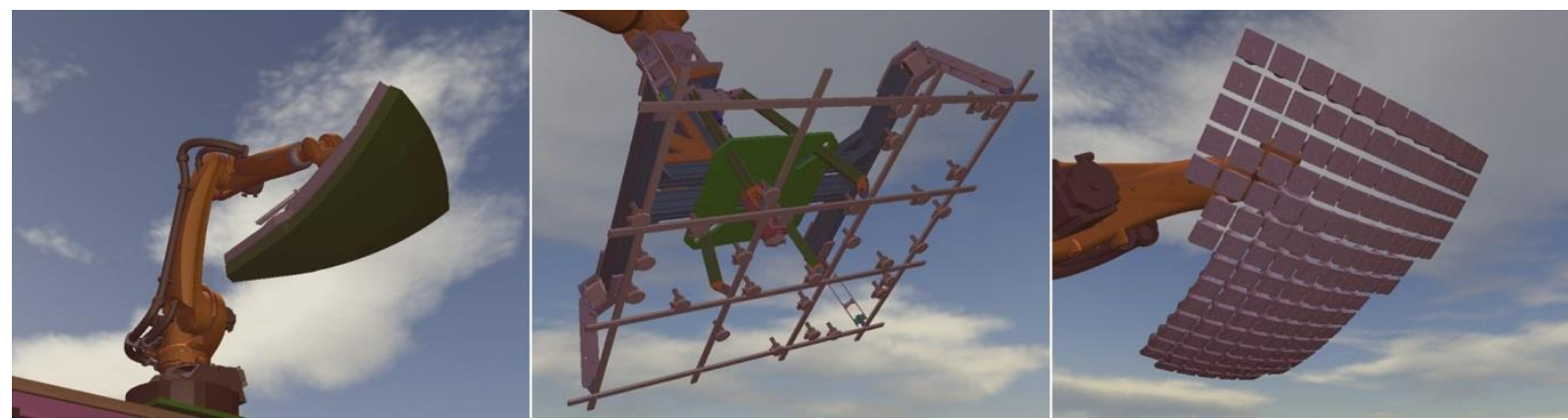

Figure 8: Modelling of gripper systems

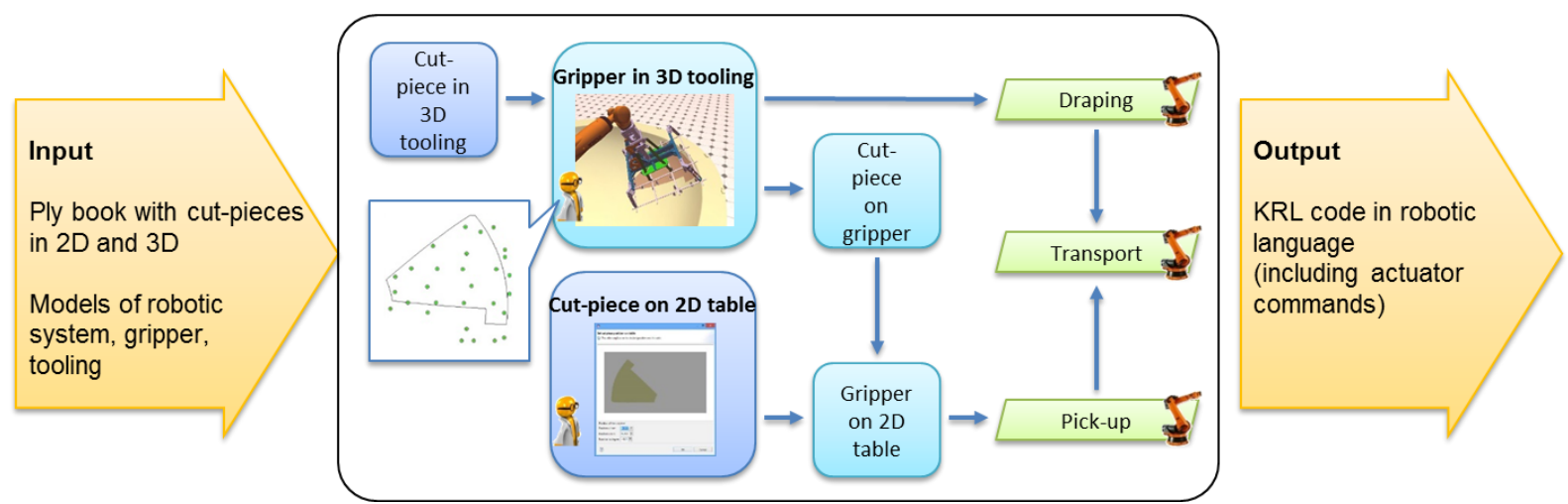

Figure 9: Offline programming of grippers

Figure 9 illustrates the procedure to obtain a ready-to-use code for the automated draping of a cutpiece. The 2D cut-piece contour is positioned on a 2D table (bottom large box). The 3D cut-piece contour on the 3D tooling surface is used to position the gripper in 3D configuration (top large box). The remaining steps are a fully automated process. The software determines the cut-piece position on the gripper in 3D, transfers this information into 2D, and derives the gripper position on the $2 \mathrm{D}$ table. The resulting gripper trajectories and actuator commands are then translated into code in robotic language. Here, a translator for KUKA Robot Language (KRL) has been used. 


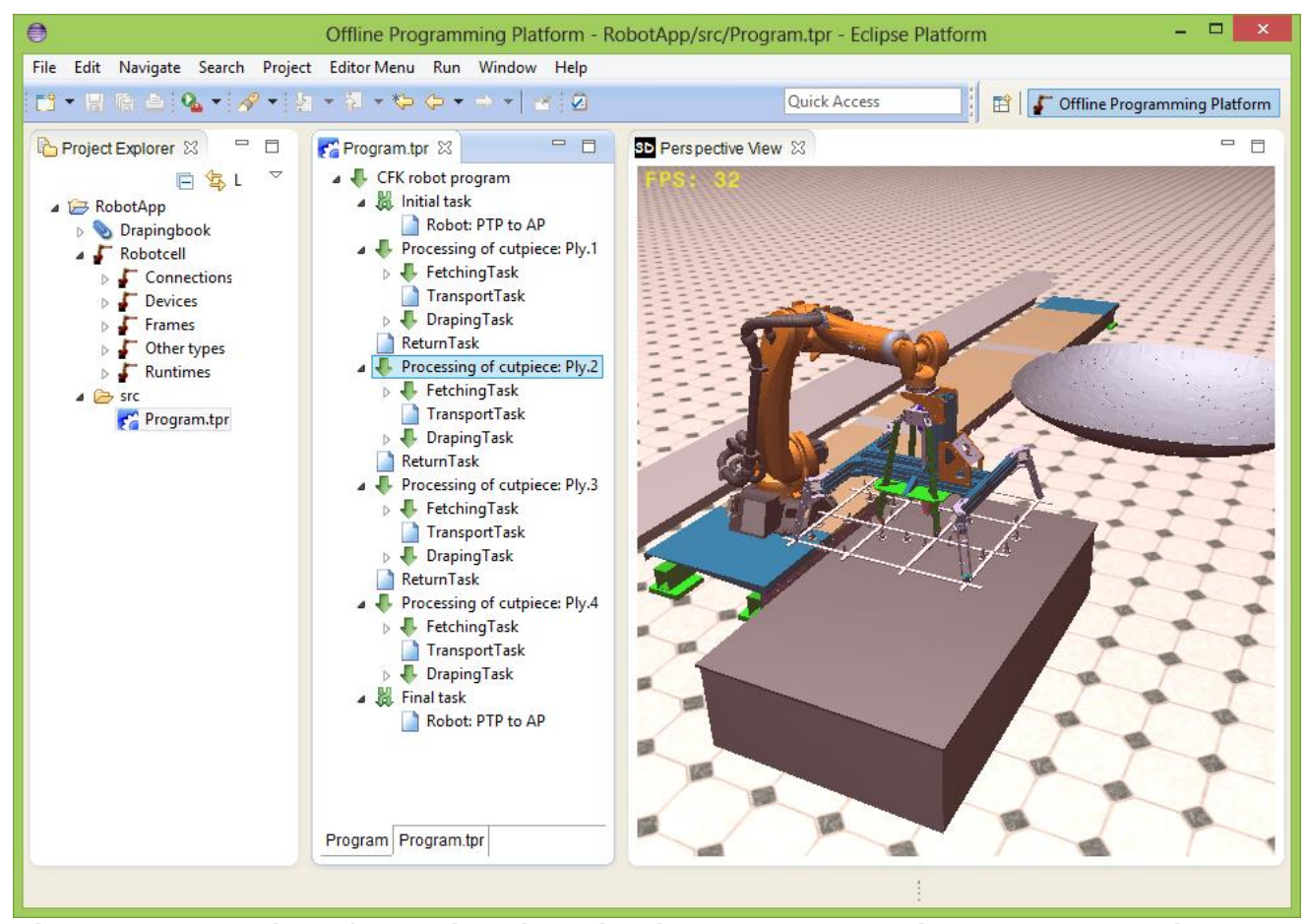

Figure 10: User interface with visualization and sequential task processing

The modular software architecture uses the extensible Robotics API framework) and features a platform containing the core functionalities (e.g. visualization, task interpretation, see Figure 10), whereas gripper specific add-ons are implemented as separate modules. Future extensions for gripper alterations, new gripper functions or entirely new gripper systems can be implemented by additional modules with the core functionalities remaining unaltered (see (ref. [10] and [11]).

\section{Production Integrated QA}

Two key parameters for preform quality made of dry carbon fiber textiles are fiber angles and cutpiece boundary positions. Both parameters can be measured during production in an accompanying inspection. From the results a proof of quality can be provided for each layer. If deviations are detected, correcting actions may be deduced while the lay-up is still in progress. Furthermore, the data could be used for finite element analysis of the actual manufacturing values, which would complete the engineering loop.

A laser light section sensor serves for measurement of the 3D cut-piece positions, see Figure 11 top row. For a quick and automated assessment of measurement data software for inline-evaluation has been developed at the DLR in Augsburg (ref. [12]). The measurement device is being guided along the boundary curve of a cut-piece whilst taking frequent line-measurements. Each line measurement yields a boundary coordinate that is being compared to the nominal value. Besides the position inspection this method can be also used for seamless fitting of cut-pieces relative to each other's boundaries.

For fiber angle measurement another optical method is applied to a robotic system, see Figure 11 bottom row. The device offers a ring light and a CMOS sensor at its center. A series of photos can be taken with illumination from different angles (ref. [13]). An automated evaluation of these photos computes an average angle per measurement area relative to a reference coordinate system, the angle distribution and local deviations. 

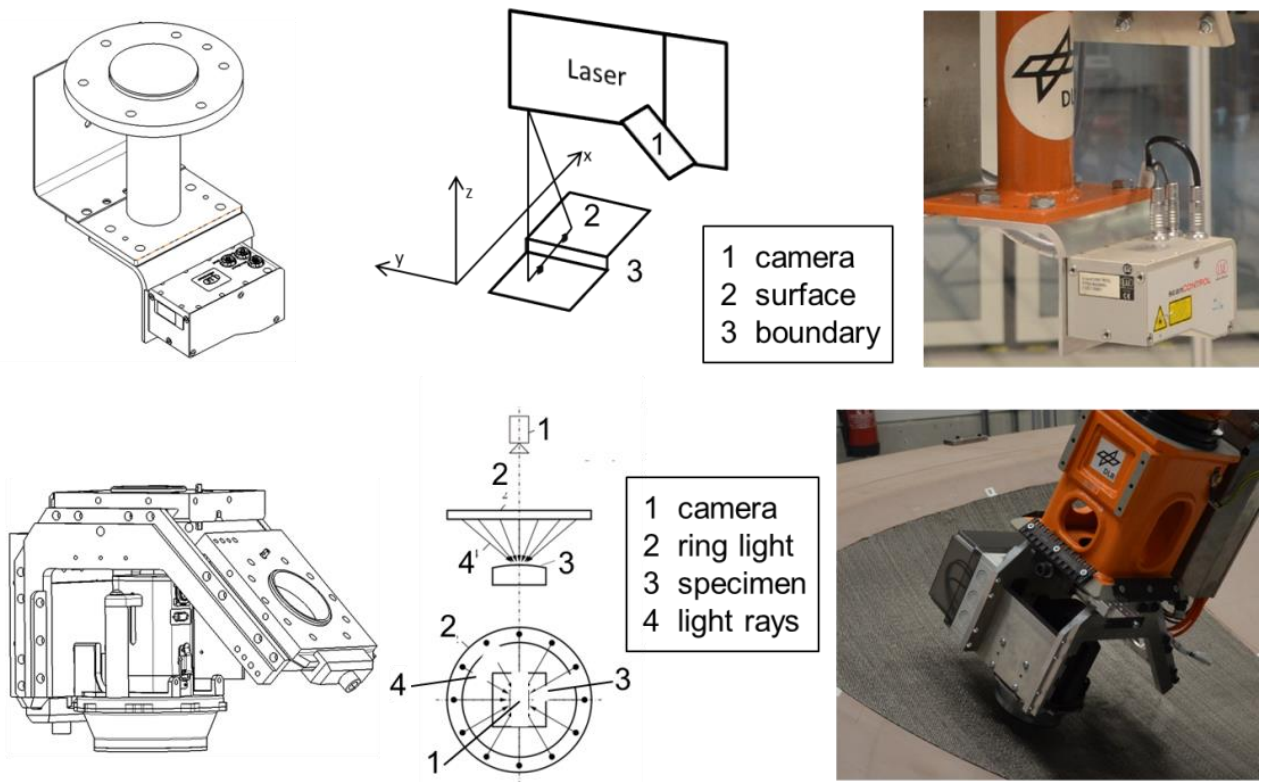

Figure 11: QA devices for cut-piece boundaries

Both systems have been integrated into robotic systems, which automatically provide data on absolute position and orientation on the specimen surface for each measurement value. Utilizing the coordinate systems of the robotic positioning device is a key advantage compared to many hand-held devices.

\begin{tabular}{|l|l|l|}
\hline & Fiber angle measurement & Boundary measurement \\
\hline Device dimension & $\begin{array}{l}450 \times 400 \times 330 \mathrm{~mm} \\
(\mathrm{LxW} \mathrm{WH})\end{array}$ & $\begin{array}{l}160 \times 256 \times 290 \mathrm{~mm} \\
(\mathrm{LxWxH})\end{array}$ \\
\hline Weight & $16.5 \mathrm{~kg}$ & $30 \mathrm{~kg}$ \\
\hline Energy supply & $\begin{array}{l}24 \mathrm{~V},<1 \mathrm{~A}(\mathrm{start} \text { current 3A), } \\
\text { EtherNet (TCP/IP) }\end{array}$ & $\begin{array}{l}24 \mathrm{~V}, 500 \mathrm{~mA} \\
\text { EtherNet (TCP/IP) }\end{array}$ \\
\hline Actuators & Sensor by Profactor & Sensor by Micro-Epsilon for \\
\hline Controls & $\begin{array}{l}\text { Robotic cell controller for robot } \\
\text { motions, triggering, image data } \\
\text { acquisition }\end{array}$ & $\begin{array}{l}\text { Measurement controller fynchronization of measurement } \\
\text { syd position data (via RSI } \\
\text { interface) }\end{array}$ \\
\hline
\end{tabular}

Table 4: Key figures of measurement devices

\section{Data Management for evaluation and documentation}

Data sources for production integrated QA typically include ultrasonic, thermography (ref. [14]), environmental data and our two devices for fiber angles and boundary curves. Whenever postproduction tests reveal irregularities an accumulation from these sources provides the base for further assessment. Accessibility of this data often determines how long otherwise finished CFRP parts remain in concession queues before being delivered

Together with Kisters $A G$ and Premium Aerotec $\mathrm{GmbH}$ the existing data management system PRAESTO has been further developed to include additional features, see Figure 12. The original scope of operation was focused on geometric measurements that could be visualized and evaluated in superposition. The new functionalities feature the integration of further sensor types, extended methods for evaluation and gathering environmental data. A new key feature is the visualization of a superposition of results from various sources in a 3D-CAD-environment (Figure 13). Hence, at any point of interest on a finished CFRP part the available measurement data can be assessed in combination. This facilitates the detection of potential mutual dependencies. 


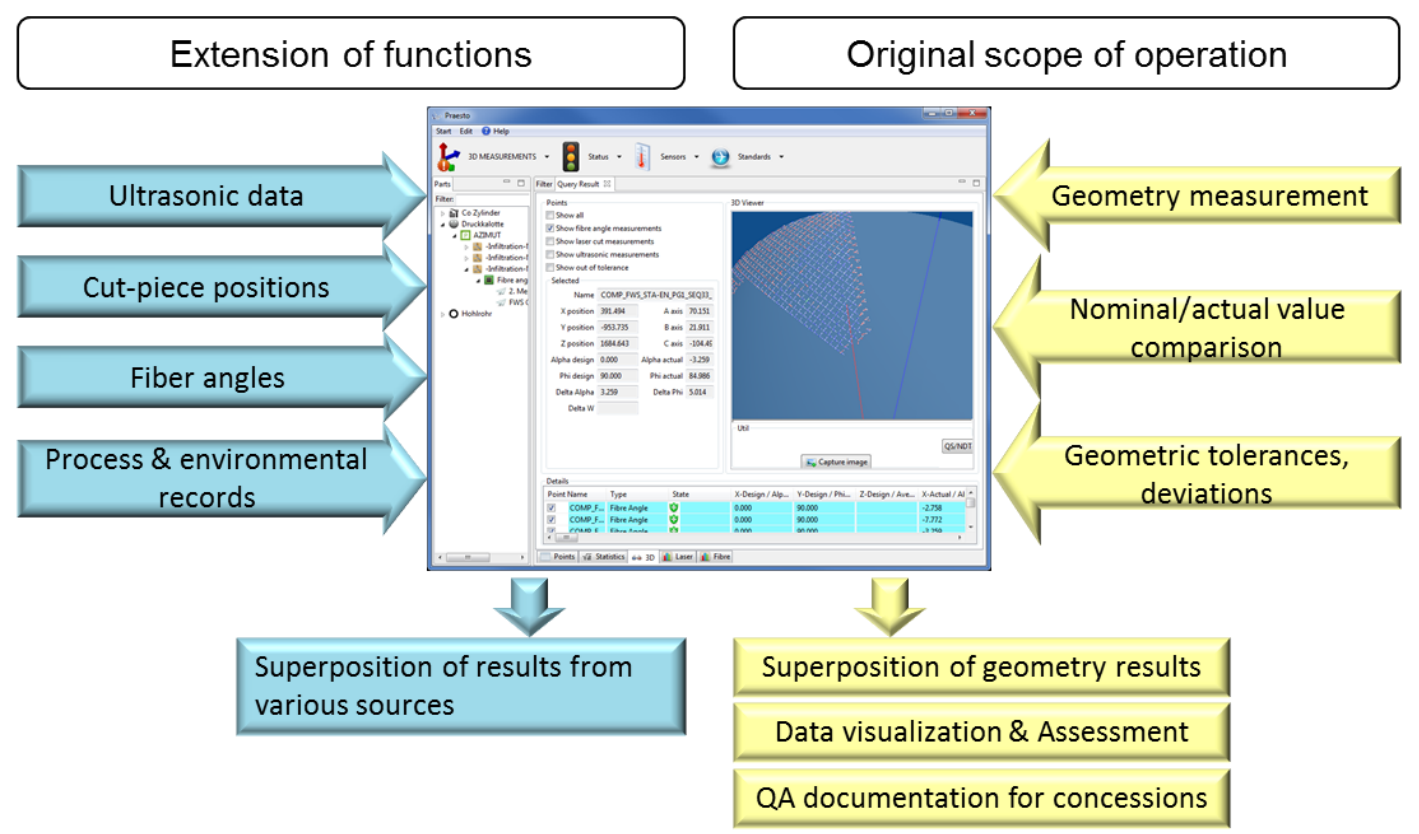

Figure 12: Data management for quality assessment

For testing and optimization a data server has been set up in the DLR infrastructure. The new user interface is web-based with user dependent visualization and access rights. Remote maintenance eases bug-fixing and optimization. The data management system is applied to CFRP process data that has been collected from various sources, see left column in Figure 12.

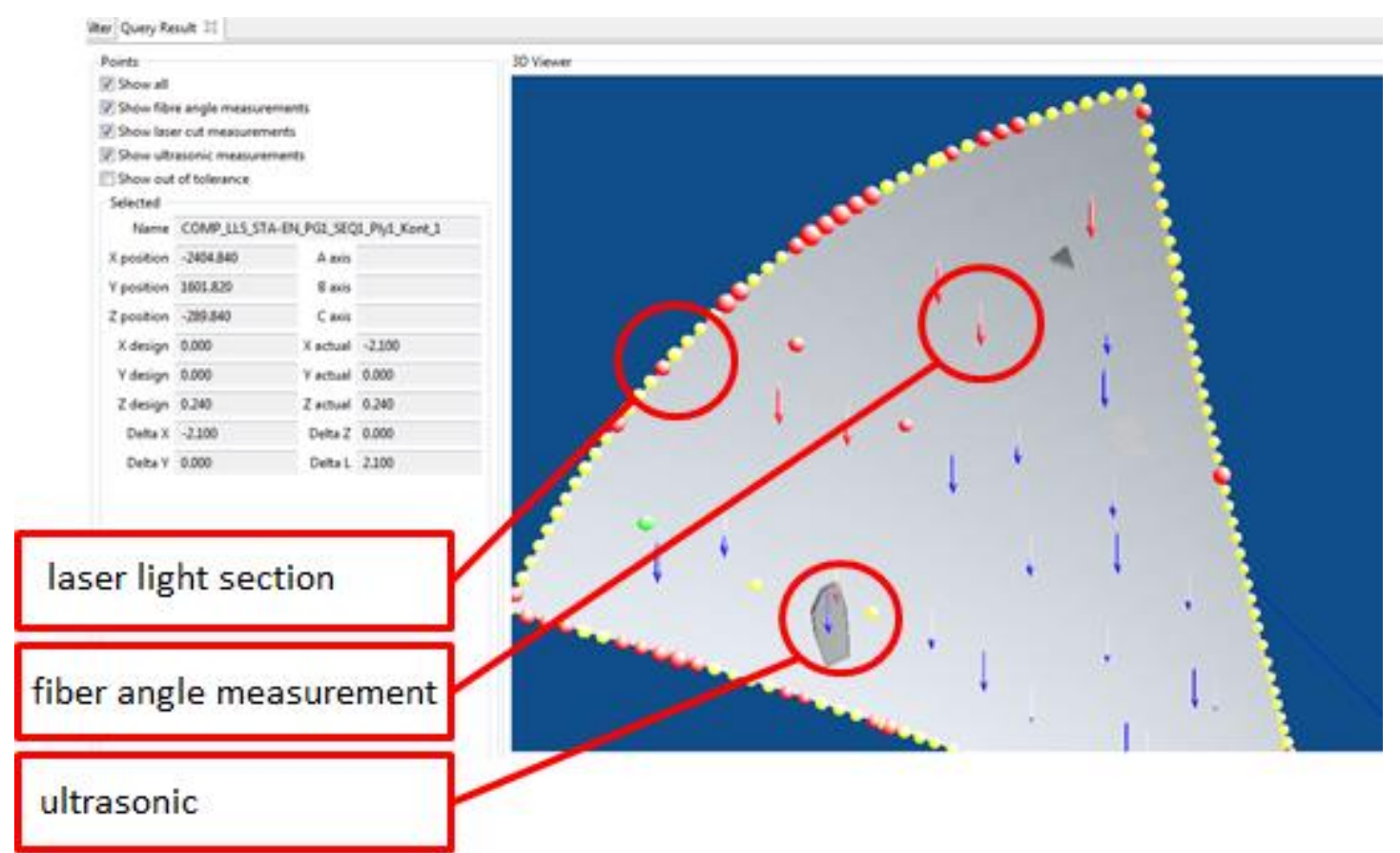

Figure 13: Visualization of superposed results from different sources

\section{Lay-up System for Auxiliary Materials}

The use case of the given bulkhead demands a VAP ${ }^{\circledR}$ (Vacuum Infusion Process) bagging and involves a time-consuming lay-up of auxiliary materials (see Figure 14) that requires close attention to manual fitting, re-positioning and application of local attachments. The automation approach focuses on a mechanized positioning device to help with quick and repeatable lay-up. 


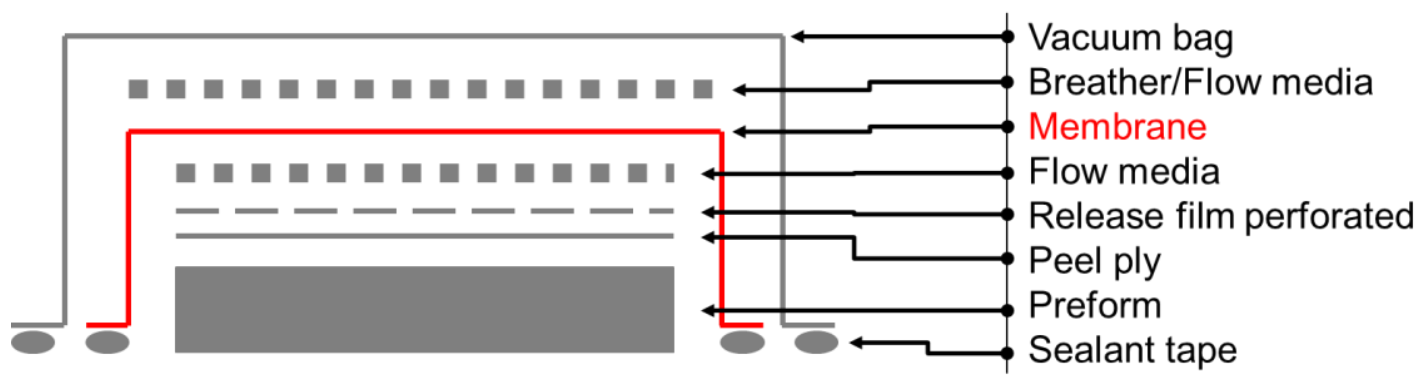

Figure 14: Auxiliary materials in VAP lay-up

As a starting point the membrane as a single layer has been selected for semi-automation, which subsequently may be extended to further auxiliary materials. The automation approach is twofold, development of a pre-tailored membrane and a mechanized lay-up device. The membrane is tailored from 17 cut-pieces by our project partners Trans-Textil GmbH and Compsyst GmbH (ref. [15]).

The lay-up device has to provide semi-automated grippers to pick-up, transport and pre-position the tailored membrane. After manual vacuum sealing and careful re-positioning of folds the device releases its cargo. To fit the doubly-curved female tooling the approach features the kinematics of an umbrella main structure with a mobile rig as positioning device, see Figure 15. For mobility of the device its only power supply is compressed air that allows the umbrella to open, close and tilt pneumatically. Each umbrella arm holds three gripper modules. These gripper modules were customized from a toggle clamp that can operate manually and pneumatically. These are essential features for sequential, manual gripper activation and collective, automatic release. After closing the toggle clamp, the gripper force remains active even without an attached power supply.

Key figures of the lay-up system see Table 5.

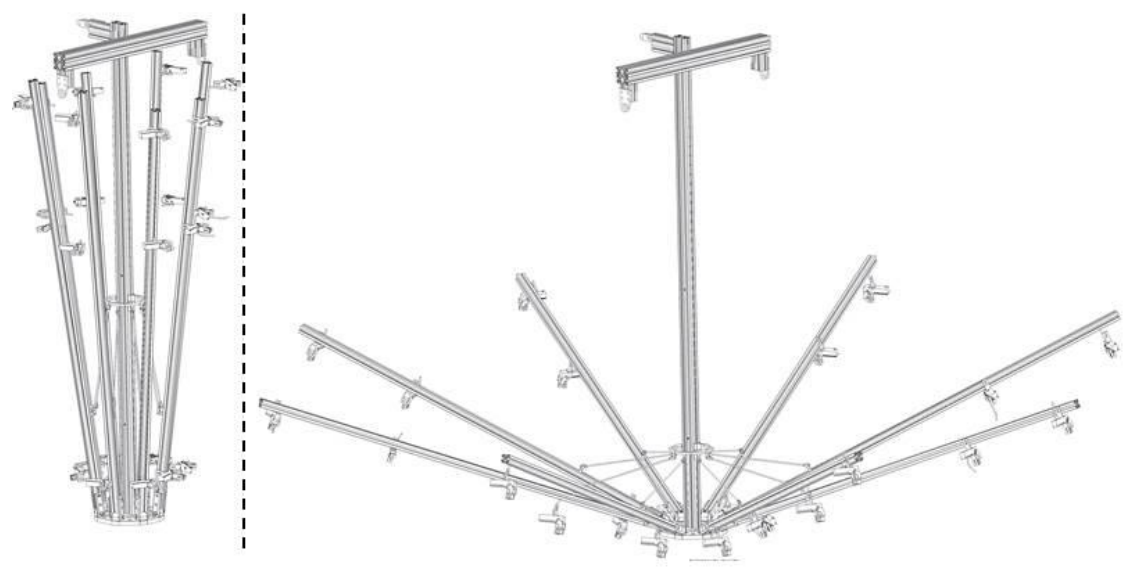

Figure 15: Mechanical semi-automated device for Lay-up of auxiliary materials

\begin{tabular}{|l|l|}
\hline & Lay-up system for auxiliary material \\
\hline Device dimension & Length: $2.5 \mathrm{~m}, \varnothing: 1.9 \mathrm{~m}$ retracted, $4 \mathrm{~m}$ deployed \\
\hline Weight & $40 \mathrm{~kg}$ \\
\hline Energy supply & Pressurized air, $6 \mathrm{bar}$ \\
\hline Actuators & Pneumatic motor, $24 \times$ pneumatic toggle clamp \\
\hline Controls & Manual valve \\
\hline
\end{tabular}

Table 5: Key figures of lay-up system for auxiliary materials 

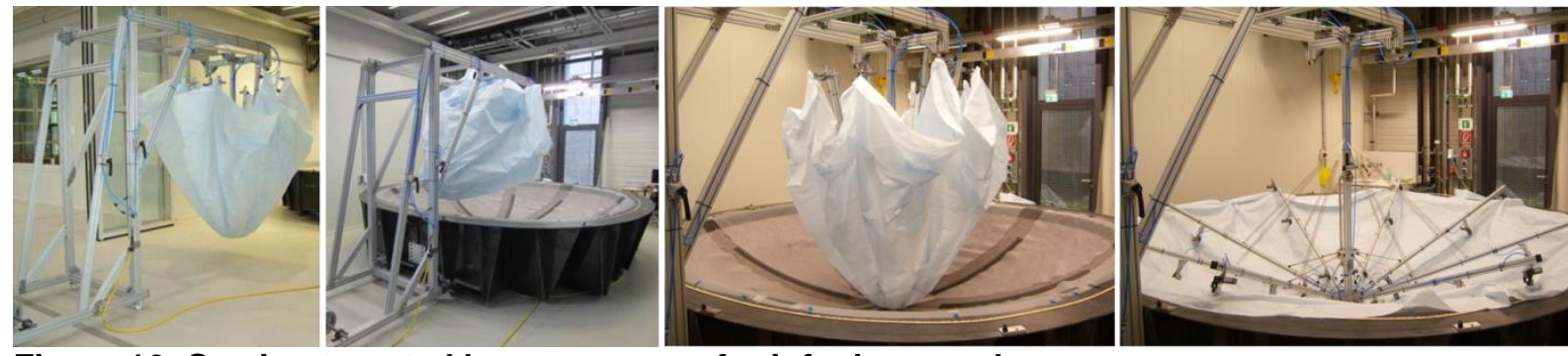

Figure 16: Semi-automated lay-up process for infusion membrane

The semi-automated lay-up process for the infusion membrane is documented in Figure 16. Firstly, the membrane is to be manually attached to the umbrella structure. Note this process step is independent of the progress in preform lay-up and tooling availability. No power source is required, since the gripper modules are manually closed. To start the actual lay-up process the mobile rig is being positioned in positioning slots at the frame of the 3D tooling. The rig can tilt the umbrella to pass the tooling rim. Next, the umbrella opens pneumatically to pre-position the membrane. Sealing between tooling rim and membrane is conducted manually. Lastly, the gripper modules can be collectively released.

This is ongoing work and the approach is currently being extended to carry further auxiliary materials.

\section{Validation}

\section{Preforming and Offline Programs}

As a final test case for the three gripper systems a set of 5 representative cut-pieces has been selected. Each gripper system had to pick-up, transport, drape and position the cut-pieces within the tolerances (fiber angle $+/-5^{\circ}$, boundary curve $+5 \mathrm{~mm} /-7.5 \mathrm{~mm}$ ). The preforming result was compared to a laser projection. Deviations of the boundary curves were measured by tape measure. Figure 17 shows a sample cut-piece with its projected boundary (left) and its evaluation (right). This nominal actual comparison was repeated for all the sample cut-pieces. While most cut-pieces with simple geometries generally tend to be within tolerances some of the more complex ones showed deviations of up to $38 \mathrm{~mm}$ (see Figure 18). For the example in Figure 18 this can be explained with the different number of gripping points in the different areas of the ply. Numerous gripping points are present at the left handed side of the cut-piece and provide a strong hold on the material. The right handed side is held only by a few grippers. This results in a varying behavior during the draping process and cannot be easily foreseen. Any adjustment made on the cut-piece position improves either the right hand-side (like done in Figure 18) or the left hand-side, but never both. Comparing the three gripper systems, this effect can be observed most prominently with the Grid Gripper but is present with the others as well. It will have to be addressed in future development, see ref. [16] and [17] for more experimental details.

Fiber angles were found to be generally within tolerance. Table 6 summarizes our observations during validation.

After determining the limits and accuracy of the gripper systems the aforementioned offline programming tool was used to generate all process parameters required for lay-up of the plybook and the according program routine in Kuka robot language. Preforming tests with those programs achieved similar accuracy as manual teaching. Time expenditure for the generation of a program for any single cut-piece proved to be between 10 and 30 minutes, depending of the complexity of the cut-piece and the applied gripper system (ref. [17]). Previous time effort for manual teaching and iterative improvements were typically between $2 \mathrm{~h}$ and 1 day for any single cut-piece. 

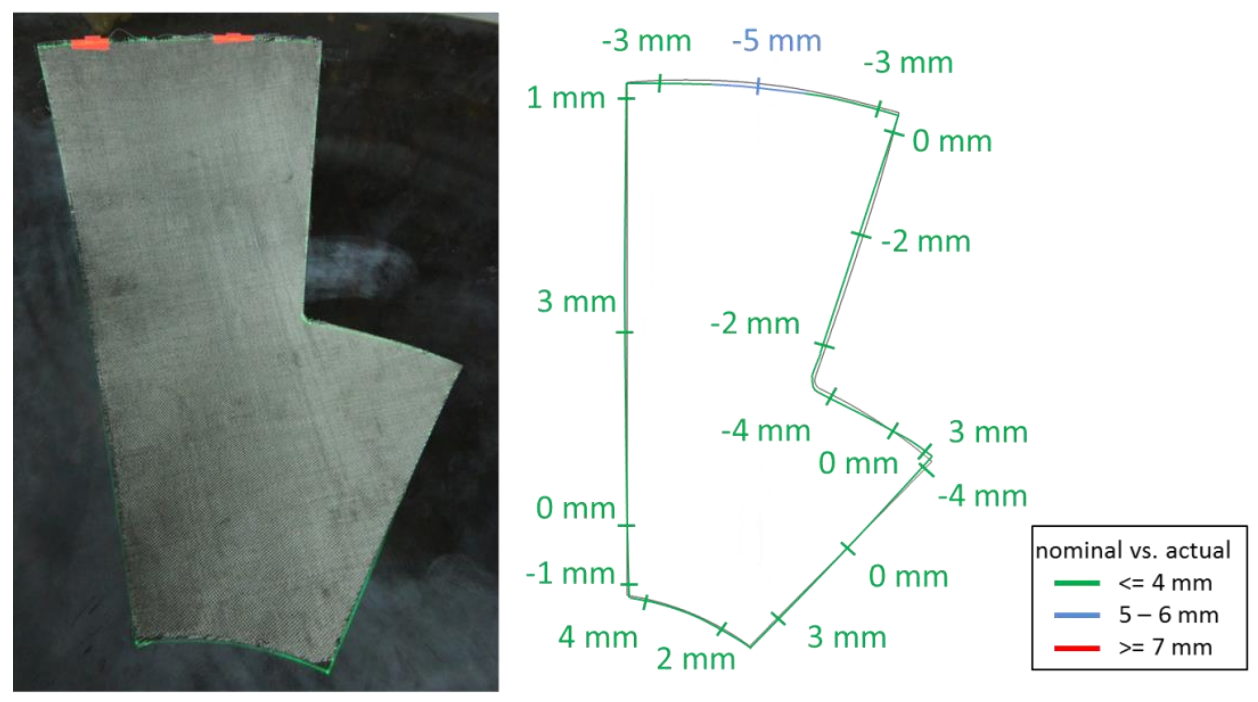

Figure 17: Example for a preforming result and its evaluation

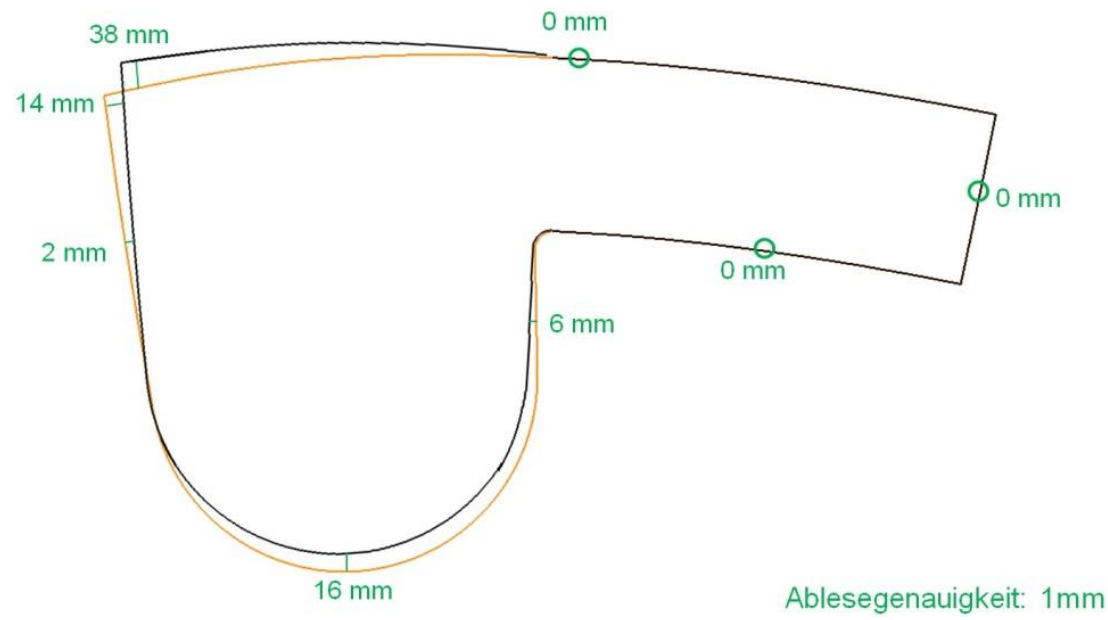

Figure 18: Cut-piece with complex geometry and preforming result

\begin{tabular}{|c|c|c|c|}
\hline & Grid Gripper & Foam Gripper & Modular Surface \\
\hline $\begin{array}{l}\text { Draping and } \\
\text { positioning } \\
\text { quality }\end{array}$ & $\begin{array}{l}\text { good results with } \\
\text { most cut-pieces, } \\
\text { slender cut-pieces } \\
\text { prone to wrinkles } \\
\end{array}$ & $\begin{array}{l}\text { reliable accuracy for small } \\
\text { and medium cut-pieces, } \\
\text { little wrinkling in case of } \\
\text { long boundaries }\end{array}$ & \begin{tabular}{|lr} 
reliable draping & and \\
positioning & within \\
tolerances & possible, \\
no wrinkles & \\
\end{tabular} \\
\hline $\begin{array}{l}\text { Usability and } \\
\text { convenience }\end{array}$ & $\begin{array}{l}\text { see-through } \\
\text { structure facilitates } \\
\text { visual inspection, } \\
\text { quick and simple } \\
\text { programming }\end{array}$ & $\begin{array}{l}\text { no visual inspection } \\
\text { before gripper removal, } \\
\text { high pressure forces } \\
\text { applied to the tooling } \\
\text { surface }\end{array}$ & $\begin{array}{l}\text { complex draping process } \\
\text { with many parameters, } \\
\text { fine adjustment of individual } \\
\text { gripper forces required, } \\
\text { no visual inspection before } \\
\text { gripper removal }\end{array}$ \\
\hline $\begin{array}{l}\text { Hardware } \\
\text { setup }\end{array}$ & \begin{tabular}{|l|} 
robust and \\
lightweight system
\end{tabular} & robust system & sensitive kinematics \\
\hline
\end{tabular}

Table 6: Observations during gripper validation 


\section{Quality Assessment Devices}

For validation of both measurement devices for fiber angles and boundary curves cut-pieces have been draped on the tooling surface according to a laser projection. Figure 19 shows both measurements and their inline evaluation in operation. For observations see Table 7.

Both devices depend on the error chain of the complete system. This includes the accuracy of the robotic cell, calibration of tools and coordinate systems and lastly the measurements system itself. In order to provide an accurate nominal/actual comparison of fiber angles and boundary curves requires still proof of system accuracy. This is ongoing work. Error chains have been defined and key errors are being addressed (see ref. [12]).
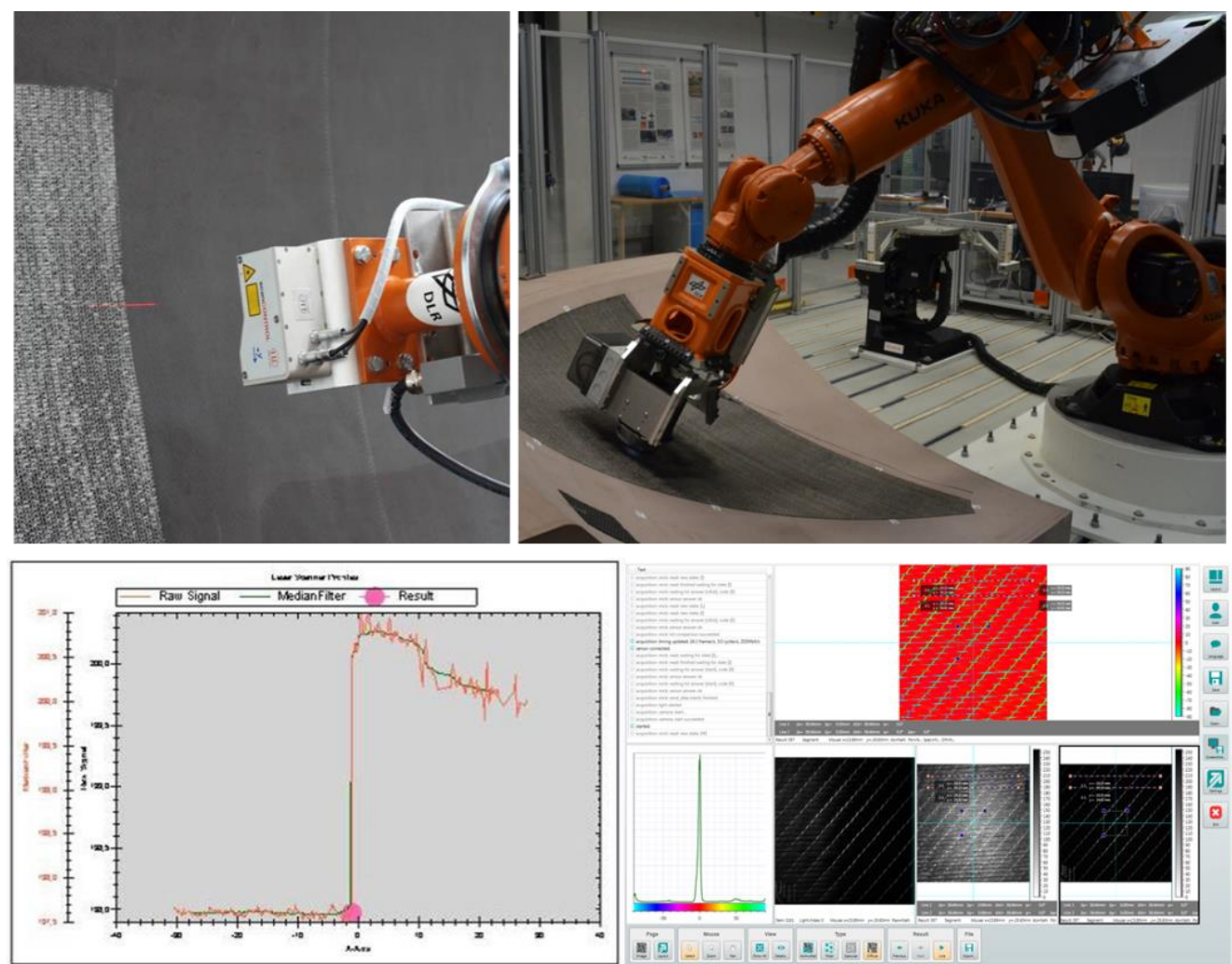

Figure 19: Measurement and evaluation boundary curves $(I)$ and fiber angles ( $r$ )

\begin{tabular}{|l|l|l|}
\hline & Boundary curves & Fiber angles \\
\hline 2D surface & $\begin{array}{l}\text { feasibility of complete measurement } \\
\text { process confirmed in 2D, } \\
\text { reference measurements carried out } \\
\text { on 2D metal reference }\end{array}$ & $\begin{array}{l}\text { Feasibility on 2D surfaces } \\
\text { confirmed, } \\
\text { most important is orientation of } \\
\text { sensor to surface }\end{array}$ \\
\hline 3D surface & $\begin{array}{l}\text { system applied to 3D surface, } \\
\text { feasibility of complete measurement } \\
\text { process confirmed in 3D, }\end{array}$ & $\begin{array}{l}\text { feasibility in 3D confirmed, } \\
\text { stop-and-go mode in operation, } \\
\text { faster scanner operation not } \\
\text { implemented yet }\end{array}$ \\
\hline Accuracy & $\begin{array}{l}\text { error chain defined and key errors } \\
\text { identified, } \\
\text { largest error from calibration of flying } \\
\text { tool center point }\end{array}$ & $\begin{array}{l}\text { Positioning accuracy dependent on } \\
\text { error chain, } \\
\text { largest error from base and tool } \\
\text { calibration }\end{array}$ \\
\hline
\end{tabular}

Table 7: Observations during operation of QA measurement devices 


\section{Auxiliary Material Lay-up Device}

The accuracy of the lay-up device and the repeatability of the positioning have been demonstrated by conducting a series of tests with the following procedure. The device has been moved to the starting point marked by mechanical stoppers. The umbrella arms have been lowered into the tooling. During this process the position of several reflectors (see Figure 20) have been recorded by a Leica Lasertracker system (accuracy $<0,05 \mathrm{~mm}$ ). This has been repeated $>10$ times. Table 8 shows the resulting maximum and median deviations in coordinate system xyz of the crane end target positon. Table 9 lists the deviation of the arm target position accordingly.

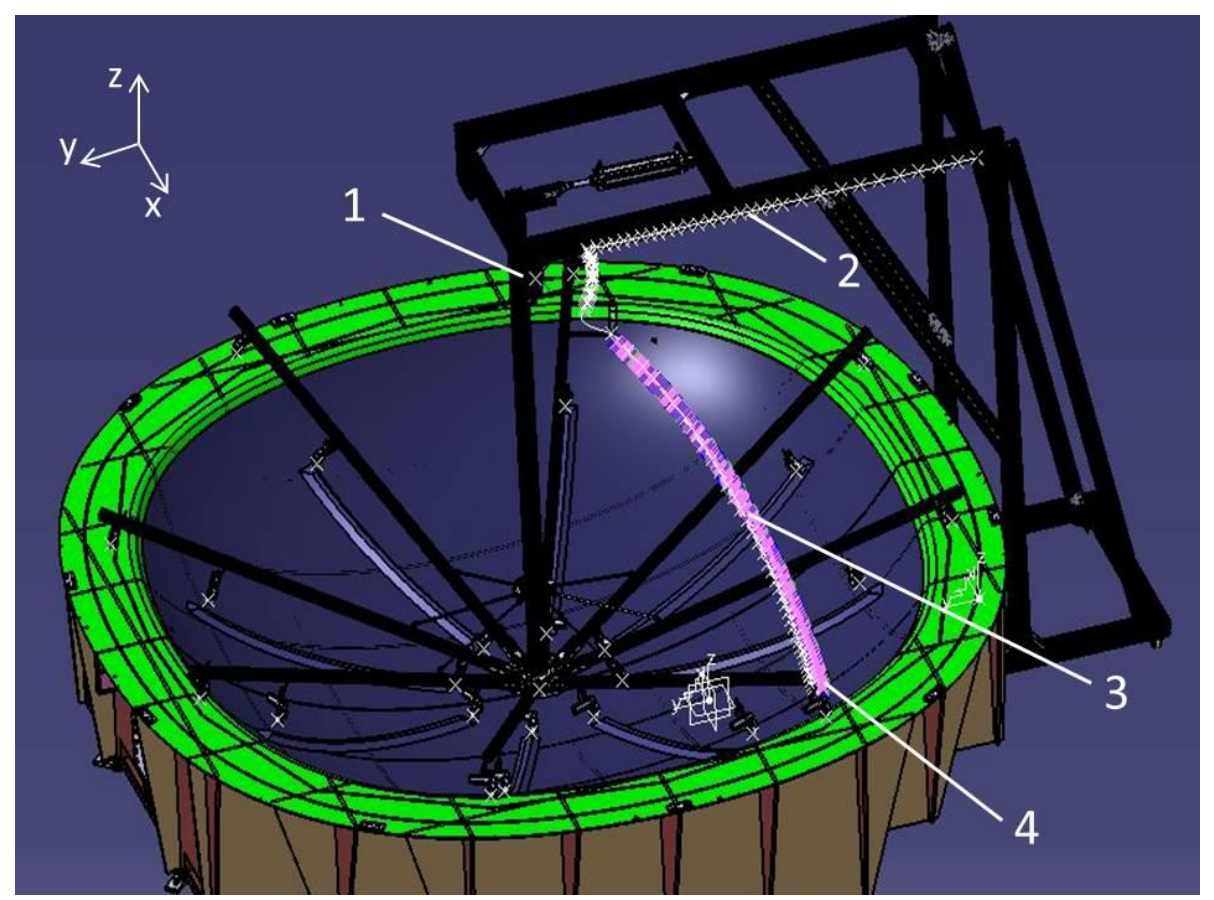

Figure 20: Measured positions of laser targets visualized in CAD: (1) end position of upper crane end, (2) path of upper crane end, (3) path of outer end of one arm, (4) end position of outer end of arm

\begin{tabular}{|l|l|l|l|}
\hline Deviation [mm] & $\mathbf{d x}$ & $\mathbf{d y}$ & $\mathbf{d z}$ \\
\hline Max. deviation & 0,72 & 1,16 & 1,88 \\
\hline Med. deviation & 0,01 & 0,09 & 0,13 \\
\hline
\end{tabular}

Table 8: Deviation of crane end target position

\begin{tabular}{|l|l|l|l|}
\hline Deviation [mm] & $\mathbf{d x}$ & $\mathbf{d y}$ & $\mathbf{d z}$ \\
\hline Max. deviation & 1,94 & 3,1 & 0,86 \\
\hline Med. deviation & 1,00 & 0,02 & 0,12 \\
\hline
\end{tabular}

Table 9: Deviation of arm end target position

The lay-up device has been validated during the manufacturing of a full scale part. The process of pick-up, positioning and draping has been successfully performed. The process is repeatable and guarantees a target position. Its support during lay-up of auxiliary materials helped in particular to reduce risk of preform alteration compared to a manual positioning. Subsequent manual draping of folds was facilitated. 
Figure 21 shows the lay-up device in operation just after pre-positioning and sealing between membrane and tooling. The manufacturing process was completed with a vacuum bagging and resin infusion and resulted in a cured part of good quality.

For further information on validation see ref. [16].

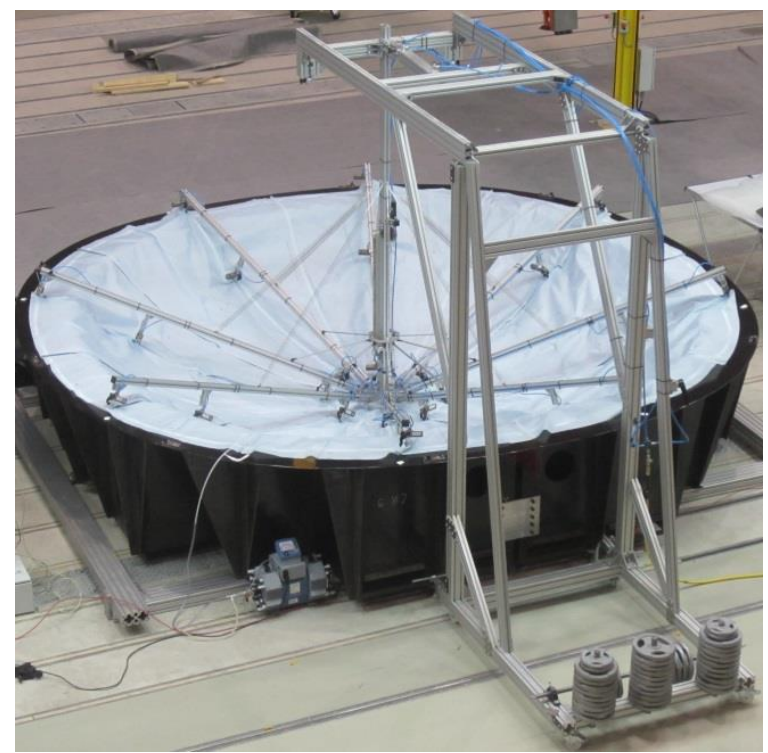

Figure 21: Lay-up device for auxiliary material in operation

\section{Discussion}

\section{Comparison of Manual Processes and Automation Approaches}

During the development of the presented automation approaches various advantages regarding reliability, repeatability, processing time and ergonomics have been observed. Three examples with potentially the most impact are as follows:

- Automated lay-up and offline programs: Handling and draping of dry textiles into a doubly curved tooling pose great challenges for an automated gripper system of which not all are addressed yet. However, the results show that gripping and transportation of sensitive textile material is possible without damage. Positioning is reproducible and often within tolerance. Most notable are the potential savings in time and manual effort in comparison to the manual process.

- Vacuum bagging: The lay-up device proved to be highly effective in positioning the auxiliary materials with the required accuracy. In contrast to the manual process no corrections are necessary and the device can be operated by a single worker. Folds are rare and within tolerance. Introduction into existing manufacturing processes can be conducted with minimal disturbance.

- Inline QA: Implementing QA into the lay-up process enables detection of deviations and corrective measures before infiltration. Defects detected at a subsequent test may lead to a rejection of the part, whereas deviations found in an early stage of the lay-up process can possibly be corrected. Automation of QA also allows tighter tolerances and results in higher reproducibility, lower variance and potentially better structural performance. Tolerances used today originate in manual production. Higher repeatability can and should lead to an adjustment. 


\section{Transferability of Results}

Initially this work started with the selection of a suitable demonstrator geometry. As a general guideline it can be postulated that dimensions and curvatures define the complexity and the challenge for the development of automation solutions. Ply book features, stiffeners and requirements (in particular tolerance requirements) add to the challenge. The pressure bulkhead was carefully selected to represent production-relevance and offer transferability of results and experiences. The following features need particular attention, when results from this work are to be transferred to other geometries:

1. Impact of curvatures and ply book on gripper systems

a. Gripper kinematics need to be able to adjust from 2D to the target 3D geometry including local curvatures.

b. Gripper size and gripper surface need to cover the different cut piece geometries and sizes in a ply book.

2. Draping design

3. Material

a. Need for draping parameters including grip points

a. Gripper technology has been optimized for given material; adjustments might include a change of suction, volume flow, gripper interface, or even active principle.

b. Knitting properties or weave type have impact on both physical drapability and draping parameters for draping design.

4. Offline programming

a. Accuracy highly depends on accurate modeling of manufacturing environment. This includes all members, e.g. tooling, transfer table for cut-pieces, projectors, robotics, mechatronic systems, ply books in both 2D and 3D.

b. Coordinate systems of a new geometry need to be suitable for manufacturing planning, i.e. referenceable in a physical environment

5. Vacuum bagging

a. Tailor-made membrane required for individual geometry

b. Concept is transferable with adjustment of kinematics

Examples for alternative geometries in Aerospace regarding complexity and challenges could be fuselages, wings, tailplanes, or cargo doors. Nowadays some of these parts are made from different composite materials. However, the results in this work may provide opportunities for future part design and a more cost-effective production.

Examples for composite parts that might be considered for a technology transfer can also be found in other industries. Potential space applications include boosters, booster domes, or main stages. Automotive industry has introduced a broad range of composite parts in nowadays vehicles. Requirements are rather different from aerospace, but examples for potential applications could be roofs or bonnets. Finally wind energy produces a variety of large scale components that might benefit from automation approaches, e.g. blade roots, shells, or spars.

\section{Lessons Learned and Remaining Challenges}

The manufacturing process in Figure 3 involves many sub-steps, where each single step requires automation or at least an approach to support dependent sub-steps. Typically, these automation approaches combine competencies from different fields, e.g. materials, design, manufacturing, QA, data management, and mechatronics. To build a fully automated process chain all single solutions require linkage to form a complete system. They need to be able to communicate, interact and react to deviations. However, today's automation approaches still have potential regarding both completeness and interconnectivity. Hence, the next step in automation development isn't necessarily yet another system for fiber lay-up or QA. Focus is needed at sub-steps in the process 
chain that are yet missing automation. And at least equally important is closing the digital gaps regarding connectivity between sub-steps and a continuous set of digital data.

This challenge may be illustrated by an observation that was made during this project with a textile lay-up. Starting off with a given ply-book (assuming it's based on realistic draping properties), a given tooling and enough textile weave (on a typical 50 inch roll) the manual process may be simplified as follows: One would use a cutter to produce cut-pieces, carry these in the right sequence to the tooling, drape them according to a laser-projection on the tooling surface, run a quality check with a hand-held device, and take a note for documentation.

To achieve an automated lay-up process, the initial tasks might be the development of a gripper system for draping and a QA system to automatically check on achieved tolerances. Let's assume some capable and reliable hardware for lay-up and QA already exists. Further let's assume that all the non-automated sub-steps may be carried out manually. To get started, again one would use a cutter to produce cut-pieces and carry these in the right sequence to the tooling. First thing missing is the information about the cut-piece in a known position without being altered (e.g. sheared) during manual transport. To get the gripper system to grip, transport and drape, one would program the system's actuators and movements. However, without an automated offline programming (OLP) approach the programs for ply books consisting of several dozen cut-pieces would cause high initial effort, only to be repeated with any future design adjustment for every single cut-piece. In addition, nowadays ply-books do not feature information for gripper systems, e.g. grip points in both 2D and 3D. Adding these retrospectively for manufacturing planning usually is hindered due to missing access to draping parameters that were used in design. After physically draping the cut piece the lay-up process requires QA. Usually fiber angles and boundary curves need to be assessed. Again, the QA system needs offline programming for every single cut-piece. Acquired 3D measurement results require a digital set-actual comparison. Compared to human visual assessment of a deviation between fibers or boundaries and a laser projection, the digital system involves long error chains in both soft- and hardware. This may become critical with submillimeter tolerances. Once a deviation has been detected, the range of possible automated reactions is still limited and further manual interaction is required. Last but not least, the lay-up process and the achieved accuracy could be digitally documented either for later assessment of potential concessions, or for reuse in a loop to the design. However, stumbling blocks regarding harmonized documentation, digital connectivity between departments, and access rights prevent this promising opportunity for improvements.

The above example shows how automated process chains require both hardware solutions and continuously interconnected digital work flows. Consequent integration of these disciplines from design to final quality assessment will offer opportunities towards a more holistic approach. A common buzzword in this context is the closed engineering loop that would allow an automated feedback loop of actual manufacturing data into engineering departments. First this would facilitate continuous improvement towards producibility, second this would enable FEM analysis with as-is data. Subsequent re-assessment of effects of defects on the quality of a finished part could potentially reduce rework or scrap.

\section{Conclusion}

This paper presented several automation approaches along the process chain for the manufacturing of large CFRP parts. For the preforming step three gripper systems were developed together with an offline programming environment for both robotic environment and gripper systems. Two measurement devices were production-integrated for inline quality assessment. A powerful data management system has been enhanced for evaluation and documentation of data from various measurements sources. Finally, a lay-up system for auxiliary materials has been developed. All automation solutions were validated on a full-scale manufacturing demonstrator resulting in a 
cured, high quality part. A final validation served as proof of functionality and feasibility in industrial scale.

However, to achieve maturity for industrial application further development is required. Gripper systems and measurement devices can be improved in performance and accuracy. Also, the devices are still stand-alone approaches that need integration into a fluent production process from start to end. For example next steps involve the setup of a complete manufacturing cycle, optimization and functional extension of the existing devices. The Center for Lightweight Production Technologies provides full-scale infrastructure to consider peripheral processes and optimize throughput.

\section{References}

[1] T. Gerngross, Ingenieur-Spiegel, Public Verl., Bingen, March, 2014, p. 50

[2] C. Ehinger, G. Reinhart, Robot-based automation system for the flexible preforming of singlelayer cut-outs in composite industry, German Academic Society for Production Engineering (WGP) 2014

[3] G. Reinhart, C. Ehinger, T. Philipp, J. Schilp, Novel Automation technologies for an efficient production of fibre reinforced plastic (FRP) structures at a glance, Setec 2011, Leiden

[4] H. Apmann, Mechatronische Handhabungsgeräte, Produktionstechnik Kolloqium 2013, Augsburg

[5] D. Sener, Handling von Faserhalbzeugen in der automatisierten CFK-Produktion, Studienarbeit, Augsburg 2011, DLR-IB 435-2011/17

[6] M.G. Emonts, Automatisierte Handhabung für die FVK-Großserienproduktion, 17. Nationales Symposium SAMPE Deutschland e.V., Conf. RWTH Aachen,

[7] M. Körber, P. Gänswürger and T. Gerngross, Deutscher Luft- und Raumfahrtkongress, Conf., Stuttgart, September 2013, DGLR, Bonn, 2013

[8] G. Reinhart and C. Ehinger, in Proc. 1st Conf. German Academic Soc. Production Engineering, Conf., Berlin, June, 2011, ISBN: 978-3-642-24490-2

[9] F. Krebs, L. Larsen, G. Braun and W. Dudenhausen, Int. J. Adv. Manuf. Technol. 73 (2014), doi=10.1007/s00170-014-6022-1

[10] A. Hoffmann, A. Angerer, A. Schierl, M. Vistein and W. Reif, in Proc. 16th Int. Conf. on Advanced Robotics, Conf., Montevideo, November, 2013

[11] L. Nägele, M. Macho, A. Angerer, A. Hoffmann, A backward-oriented approach for offline programming of complex manufacturing tasks, International Conference on Automation, Robotics and Applications (ICARA 2015)

[12] L. Larsen, S. Dutta, Inline Qualitätssicherung in der CFK-Produktion mittels Laserscanner, Produktion 2020: Einsatz, Verarbeitung und Prüfung von Leichtbau- und Faserverbundwerkstoffen, Conf. 2011, DLR-IB 435-2011/60

[13] W. Palfinger, S. Thumfart and C. Eitzinger, 35th Workshop of the Austrian Association for Pattern Recognition, Conf., Graz, Mai, 2011 
[14] T. Schmidt and S. Dutta, 5th Int. Symp. on NDT in Aerospace, Conf., Singapore, November, 2013

[15] A. Hänsch and S. Utecht, Composites World, Gardner Business Media, Cincinatti, July, 2013, p.15

[16] D. Nieberl, C. Schmidt-Eisenlohr, M. Körber, AZIMUT Halbjahresbericht 02/13, Projektbericht, DLR-IB 435-2013/54

[17] D. Nieberl, C. Schmidt-Eisenlohr, M. Körber, AZIMUT Halbjahresbericht 01/14, Projektbericht, DLR-IB 435-2014/39 